\title{
Diagnosing Xpert MTB/RIF-negative TB: Impact and cost of alternative algorithms for South Africa
}

\author{
K Schnippel, G Meyer-Rath, L Long, W S Stevens, I Sanne, S Rosen \\ Health Economics and Epidemiology Research Office, Department of Internal Medicine, School of Clinical Medicine, Faculty of Health Sciences, \\ University of the Witwatersrand, Johannesburg \\ K Schnippel, MPA \\ L Long, MComm
}

Center for Global Health and Development, Boston University, Boston, USA; and the Health Economics and Epidemiology Research Office, Department of Internal Medicine, School of Clinical Medicine, Faculty of Health Sciences, University of the Witwatersrand, Johannesburg G Meyer-Rath, MD, PhD

I Sanne, FCP, DTM\&H

S Rosen, MPA

Department of Molecular Medicine and Haematology, Faculty of Health Sciences, University of the Witwatersrand; and the National Health Laboratory Service, Johannesburg.

W S Stevens, MB BCh, MMed (Haematology), FCPath (Haematology)

Corresponding author: K Schnippel (kschnippel@heroza.org)

\begin{abstract}
Background. Use of Xpert MTB/RIF is being scaled up throughout South Africa for improved diagnosis of tuberculosis (TB). A large proportion of HIV-infected patients with possible TB are Xpert-negative on their initial test, and the existing diagnostic algorithm calls for these patients to have sputum culture (Xpert followed by culture $(\mathrm{X} / \mathrm{C})$ ). We modelled the costs and impact of an alternative diagnostic algorithm in which these cultures are replaced with a second Xpert test (Xpert followed by Xpert (X/X)).

Methods. An existing population-level decision model was used. Costs were estimated from Xpert implementation studies and public sector price and salary data. The number of patients requiring diagnosis was estimated from the literature, as were rates of TB treatment uptake and loss to follow-up. TB and HIV positivity rates were estimated from the national TB register and laboratory databases.

Results. At national programme scale in 2014, X/X (R969 million/year) is less expensive than X/C R1 095 million/year), potentially saving R126 million/year (US\$17.4 million). However, because Xpert is less sensitive than culture, $\mathrm{X} / \mathrm{X}$ diagnoses $2 \%$ fewer TB cases. This is partly offset by higher expected treatment uptake with $\mathrm{X} / \mathrm{X}$ due to the faster availability of results, resulting in $1 \%$ more patients initiating treatment under $\mathrm{X} / \mathrm{X}$ than X/C. The cost per TB patient initiated on treatment under X/X is R2 682, which is $12 \%$ less than under X/C (R3 046).

Conclusions. Modifying the diagnostic algorithm from $\mathrm{X} / \mathrm{C}$ to $\mathrm{X} / \mathrm{X}$ could provide rapid results, simplify diagnostic processes, improve HIV/TB treatment outcomes, and generate cost savings.

S Afr Med J 2013;103(2):101-106. DOI:10.7196/SAMJ.6182
\end{abstract}

The availability of Xpert MTB/RIF offers the potential for rapid, accurate diagnosis of tuberculosis (TB). ${ }^{1}$ This has generated new hope in resource-constrained countries with high burdens of TB/HIV co-infection. It has also created a dilemma: how to manage patients with TB symptoms who receive a negative Xpert test result for their initial sputum sample. HIV co-infection often results in a low TB bacillary load in sputum, so the sensitivity of acid-fast bacilli smear microscopy (AFB) is only $38-47 \%$ in this population. ${ }^{2,3}$

The World Health Organization (WHO) has recommended Xpert as the first-line diagnostic for adult patients with possible HIV/TB co-infection. ${ }^{4}$ However, the sensitivity of a single Xpert test in AFB-negative patients, estimated at $62-79 \%$, is also inadequate, though substantially better than for AFB. ${ }^{1,5,6}$ Meanwhile, TB has relatively rapid disease progression and high mortality rates in HIVinfected subjects. ${ }^{7}$ The high proportion of these patients who are left undiagnosed after a single Xpert test is therefore a concern.

In $\mathrm{SA}$, the $\mathrm{TB} / \mathrm{HIV}$ co-infection rate is estimated at $60 \%{ }^{8}$ In March 2011, the country announced its intention of replacing smear microscopy with Xpert for TB diagnosis. In 2011, the National Health Laboratory Service (NHLS) completed over 5 million sputum smear microscopy tests, including samples for TB treatment monitoring and diagnosis. This represents an approximate $10 \%$ increase over the previous year, due in part to national campaigns for intensified TB and HIV case finding. Assuming that this rate of annual growth can be maintained then in 2014, once Xpert has been fully rolled out across SA, 2.5 million persons with TB symptoms will be tested with it.

According to SA's current diagnostic algorithm for pulmonary TB (PTB), HIV-infected patients with possible TB whose first Xpert test was negative have to return to the clinic and provide a second sputum sample to be sent for culture. The patient is also asked to undergo a clinical examination and chest X-ray and started on presumptive antibiotic therapy. ${ }^{9} \mathrm{~A}$ model developed to estimate the cost of implementing Xpert MTB/RIF in South Africa highlights the cost of this diagnostic challenge. ${ }^{10}$

Assuming both a stable TB epidemic and a stable HIV epidemic, in 2014 approximately 1.4 million HIV-infected persons, comprising $53 \%$ of all patients with possible $\mathrm{TB}$, will test Xpert-negative but possibly still have TB. Although the current algorithm provides 'gold standard' for diagnostic results, it is expensive. The 53\% of patients with possible $\mathrm{TB}$ who will require culture after Xpert 


\section{RESEARCH}

will account for $60 \%$ of the total cost of diagnosing PTB in South Africa. ${ }^{9}$ Approximately $3 \%$ of these Xpert-negative patients will have a positive culture result, accounting for only $10 \%$ of all $\mathrm{TB}$ cases diagnosed in South Africa. A very large share of resources will therefore be spent to identify just $10 \%$ of TB patients. Culture results, moreover, are only available 2 - 6 weeks after sputum collection. With limited laboratory capacity, delays in sample transport, and weak information and patient follow-up systems, results may only reach patients months later, if at all. This delay contributes to a high rate of patient loss to follow-up after initial clinic presentation. ${ }^{1}$

Studies indicate that Xpert sensitivity increases with additional sputum samples tested. ${ }^{6,11}$ Because of the relatively high cost of Xpert MTB/RIF cartridges, however, algorithms using multiple Xpert tests have been confined to research. One modelling effort concluded that, compared with the use of two cultures or a single Xpert, an algorithm containing two Xpert tests was cost-effective in a pre-antiretroviral therapy (ART) population, regardless of the presence of TB symptoms. ${ }^{12}$

However, the differences between the modelled population and algorithms and the current standard of care in SA make this finding difficult to apply to the national diagnostic algorithm.

We set out to inform debates about the optimal use of Xpert in diagnosis of PTB in a context of high TB/HIV co-infection and low rates of AFB-positivity among patients with possible TB. To do this, we estimated the impact and costs of an alternative diagnostic algorithm in which culture, X-ray and antibiotic therapy (current Xpert diagnostic algorithm, abbreviated as Xpert/culture, or $\mathrm{X} / \mathrm{C}$ ) are replaced by a second Xpert test using a second sputum sample (proposed Xpert algorithm, abbreviated as Xpert/Xpert, or X/X). We used a national-level model projecting the costs of reaching full coverage with Xpert technology, developed by our team for the South African Department of Health in 2011. ${ }^{10}$

\section{Methods}

The National TB Cost Model captures the TB diagnostic process, starting with patients with possible $\mathrm{TB}$, continuing to $\mathrm{TB}$ cases, and ending with completion of TB treatment. ${ }^{10}$ This populationlevel decision model estimates numbers of $\mathrm{TB}$ cases and costs for the financial years 2011 to 2016, with full-scale Xpert roll-out and implementation achieved in 2014. All results reported here are extrapolations for 2014. The development of the National TB Cost Model was approved by the Human Research Ethics Committee of the University of the Witwatersrand and the Institutional Review Board of Boston University Medical Campus.

\section{Scenarios and algorithms}

The model follows quarterly cohorts of TB patients with possible TB through up to three diagnostic visits under two scenarios. The $\mathrm{X} / \mathrm{C}$ scenario represents the current Xpert diagnostic algorithm for patients with possible $\mathrm{TB} / \mathrm{HIV}$ co-infection. Under $\mathrm{X} / \mathrm{C}$, an initial negative Xpert is followed by a second visit comprising a TB culture using a second sputum sample, a clinical examination, a chest X-ray, and antibiotic therapy. The $\mathrm{X} / \mathrm{X}$ scenario is the alternative diagnostic algorithm, in which the visit that follows an initial negative Xpert is comprised of a second Xpert using a second sputum sample, and omits

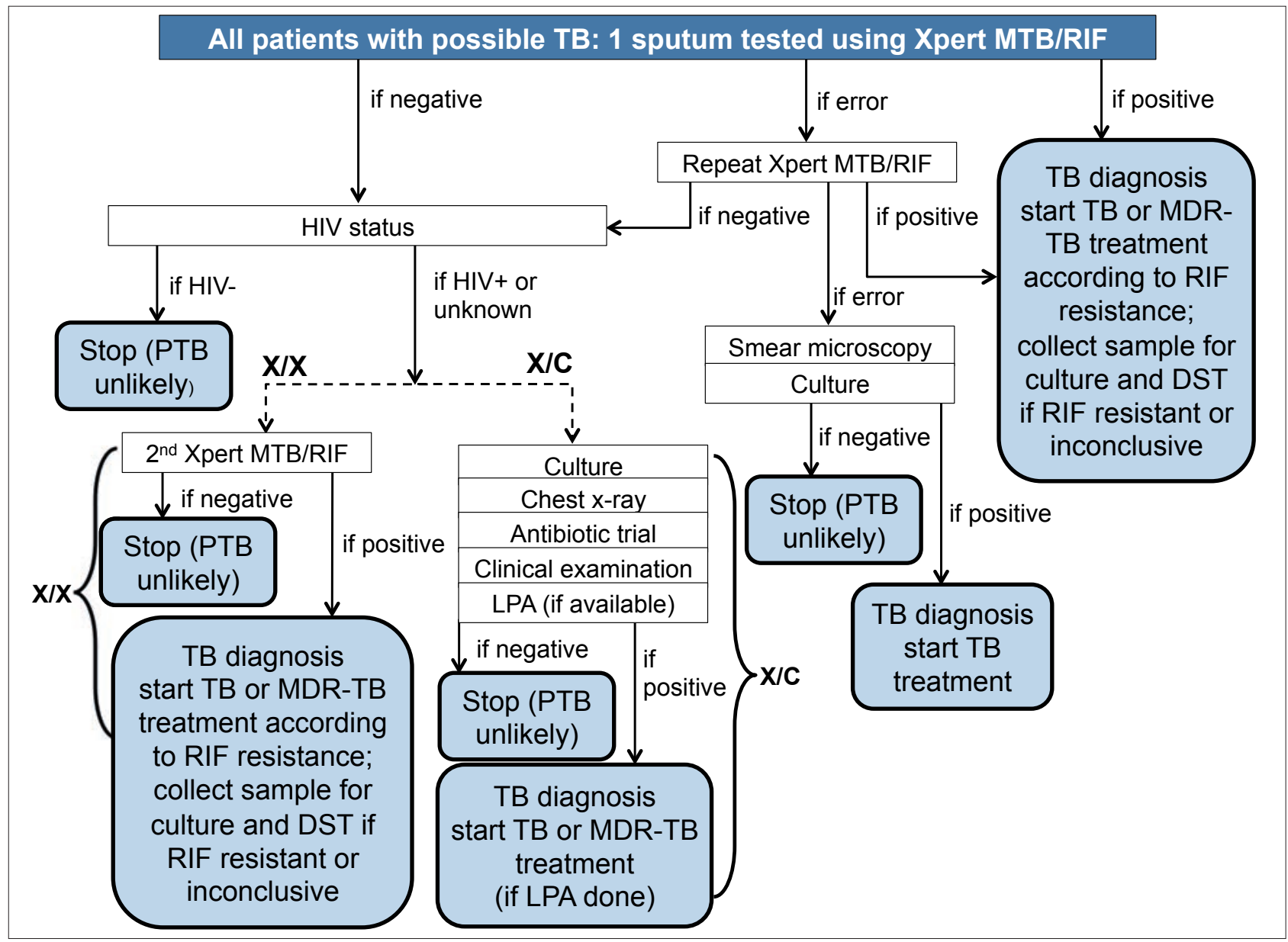

Fig. 1. Xpert/culture $(X / C)$ and Xpert/Xpert $(X / X)$ pulmonary TB diagnostic algorithms (adults $>15$ years). MTB = Mycobacterium tuberculosis; $P T B=$ pulmonary $T B ; M D R-T B=$ multi-drug resistant $T B ; R I F=$ rifampicin (resistance); $L P A=$ line probe assay. 
the other procedures (culture, examination, X-ray, and antibiotics).

Under both scenarios, patients are counted as diagnosed even if they fail to return to receive their results, though such patients would not be assumed to initiate treatment. As per South African TB guidelines, patients with a positive AFB, culture, or Xpert result are counted as having TB, meaning that the effective specificity of these tests is assumed to be $100 \%$. Fig 1 illustrates the diagnostic algorithms used in this analysis.

The number of patients to be evaluated for TB (i.e. patients

\section{Table 1. Model inputs and assumptions}

\begin{tabular}{|c|c|c|}
\hline Parameter & $\begin{array}{l}\text { Value in } \\
2014\end{array}$ & Source \\
\hline $\begin{array}{l}\text { Coverage of Xpert MTB/RIF } \\
\text { (sub-districts) }\end{array}$ & $100 \%$ & NHLS 2012 \\
\hline $\begin{array}{l}\text { Coverage of line probe assay for } \\
\text { RIF+INH detection (provincial) }\end{array}$ & $62 \%$ & $\begin{array}{l}\text { NHLS TB } \\
\text { database }\end{array}$ \\
\hline $\begin{array}{l}\text { Coverage of fluorescent smear } \\
\text { microscopy (sub-districts) }\end{array}$ & $100 \%$ & $\begin{array}{l}\text { NHLS TB } \\
\text { database }\end{array}$ \\
\hline $\begin{array}{l}\text { Coverage of liquid culture, } \\
\text { including DST (provincial) }\end{array}$ & $100 \%$ & $\begin{array}{l}\text { NHLS TB } \\
\text { database }\end{array}$ \\
\hline Coverage of chest X-ray & $100 \%$ & Assumption \\
\hline $\begin{array}{l}\text { TB incidence, per } 100000 \\
\text { population }\end{array}$ & 981 & $\mathrm{WHO}^{8}$ \\
\hline $\begin{array}{l}\text { Annual growth in number of } \\
\text { patients to be evaluated for TB }\end{array}$ & $10 \%$ & SANAC $^{21}$ \\
\hline $\begin{array}{l}\text { Number of patients to be } \\
\text { evaluated for TB }\end{array}$ & 2573504 & Meyer-Rath et al. ${ }^{10}$ \\
\hline $\begin{array}{l}\text { Proportion of patients with } \\
\text { possible TB known to be HIV+ }\end{array}$ & $56 \%$ & ETR 2010 \\
\hline $\begin{array}{l}\text { Proportion of patients with } \\
\text { possible TB, HIV status unknown } \\
\text { (managed as if HIV+) }\end{array}$ & $6 \%$ & ETR 2010 \\
\hline $\begin{array}{l}\text { Proportion sputum smear+ } \\
\text { (2 sputa) }\end{array}$ & $7 \%$ & $\begin{array}{l}\text { NHLS TB } \\
\text { database }\end{array}$ \\
\hline Proportion culture+ if smear- & $9 \%$ & $\begin{array}{l}\text { NHLS TB } \\
\text { database }\end{array}$ \\
\hline RIF + INH resistance (MDR-TB) & $3 \%$ & Weyer et al..$^{22}$ \\
\hline Xpert MTB sensitivity, smear+ & $100 \%$ & Boehme et al. ${ }^{1}$ \\
\hline Xpert MTB sensitivity, smear- & $79 \%$ & Boehme et al. ${ }^{1}$ \\
\hline Xpert MTB/RIF failure rate & $2 \%$ & Meyer-Rath et al. ${ }^{10}$ \\
\hline RIF resistance & $3 \%$ & Weyer et al..$^{22}$ \\
\hline Xpert RIF sensitivity & $90 \%$ & Boehme et al. ${ }^{1}$ \\
\hline $\begin{array}{l}\text { Proportion lost to follow-up at } \\
\text { visits } 1,2,3\end{array}$ & $\begin{array}{l}13 \%, 26 \% \\
39 \%\end{array}$ & $\begin{array}{l}\text { Boehme et al. }{ }^{1} \text {, } \\
\text { assumption }\end{array}$ \\
\hline $\begin{array}{l}\text { Proportion lost to follow-up } \\
\text { or dead, 1st-line treatment }\end{array}$ & $14 \%$ & $\mathrm{WHO}^{8}$ \\
\hline $\begin{array}{l}\text { Proportion lost to follow-up } \\
\text { or dead, MDR-TB treatment }\end{array}$ & $30 \%$ & $\mathrm{DoH}^{9}$ \\
\hline $\begin{array}{l}\text { Proportion of patients with } \\
\text { MDR-TB who develop XDR-TB }\end{array}$ & $10 \%$ & $\mathrm{WHO}^{8}$ \\
\hline $\begin{array}{l}\text { Proportion of patients who die } \\
\text { during XDR-TB treatment }\end{array}$ & $36 \%$ & Dheda et al..$^{17}$ \\
\hline \multicolumn{3}{|c|}{ 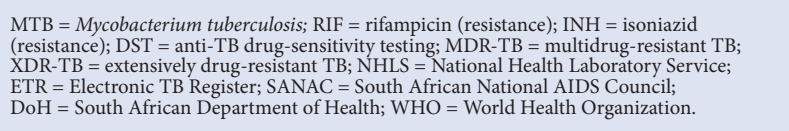 } \\
\hline
\end{tabular}

with a positive TB symptom screen) was calculated using data on the general population aged 15 years and above from the Actuarial Society of South Africa AIDS Model, ${ }^{13}$ as well as an assumption of prevalence of TB symptoms of $5.5 \%$ based on the Provincial Quarterly TB Reports. ${ }^{14}$ Based on analysis of the NHLS 2010 database, $20 \%$ of patients evaluated in 2011 were found to be TB positive. This rate decreases over time as a function of case finding initiatives (increased numbers of patients evaluated for TB), allowing us to model a stable epidemic.

\section{Diagnostic parameters}

AFB, culture, and HIV positivity rates for the model were estimated from a random sample of all patients entered into the national-level National Health Laboratory Service (NHLS) 2010 TB specimen database, and a random sample of all patients entered into the national-level 2010 Electronic TB Register. For this analysis, the model was updated with results of the pilot phase of national Xpert implementation through to the end of February 2012. Table 1 lists the model inputs and assumptions and their sources.

\section{Cost parameters}

Cost parameters are presented in Table 2. We calculated the cost of TB diagnosis from the government perspective, including the cost of outpatient visits, antibiotics, and laboratory and radiological tests. We used expert opinion and public-sector salary data to estimate the duration and cost of clinic visits, and 2011 NHLS charges for all laboratory costs except the Xpert test.

The new NHLS charge for the Xpert test, including the local price of cartridge procurement, operator time, sputum transport, quality assurance, and laboratory operating overheads, was set at R166 after the announcement of a global price reduction for Xpert MTB/RIF cartridges to US $\$ 9.98 .^{15}$

No costs for MDR-TB treatment have been published for South Africa. We therefore used WHO CHOICE unit costs for inpatient days at publicsector tertiary-level hospitals, as well as outpatient visits at secondarylevel hospitals, ${ }^{16}$ to estimate costs for drug-resistant TB treatment according to new South African policy guidelines issued in $2011 .{ }^{9} \mathrm{WHO}$ CHOICE costs for outpatient visits at health facilities with no beds were used for drug-sensitive TB treatment. Current estimates for patient lossto-follow-up and death during $\mathrm{TB}$ treatment ${ }^{8,9,17}$ were incorporated, and 2011 public-sector drug costs were applied to standardised regimens. Costs are reported in ZAR at 2011 exchange rates (US\$1 = ZAR 7.23), ${ }^{18}$ undiscounted and excluding value-added tax.

\section{Sensitivity analysis}

In sensitivity analysis, we systematically varied eight central parameters:

- $+/-25 \%$ in the cost of the Xpert test

- $+/-25 \%$ in the proportion of patients with possible TB who have known HIV infection ${ }^{5}$

- $+/-50 \%$ in the proportion of patients lost at each visit

- $+/-20 \%$ in Xpert sensitivity for smear-negative $\mathrm{TB}^{6}$

- $+/-50 \%$ in the proportion of TB which is smear positive ${ }^{11}$

- $+/-50 \%$ in the TB positivity rate

- $+/-50 \%$ access to LPA testing

- $+/-50 \%$ proportion testing rifampicin resistant.

The per cent variation for each parameter was based on its variation in published literature.

\section{Results}

At full scale-up in 2014, the current diagnostic algorithm, X/C, will cost an estimated R1 095 million (Table 3). The alternative algorithm, X/X, will cost $\mathrm{R} 969$ million. $\mathrm{X} / \mathrm{X}$ thus generates a total 


\section{RESEARCH}

Table 2. Cost inputs

\begin{tabular}{|c|c|c|}
\hline Input & $\begin{array}{l}\text { Unit cost } \\
(2011 \mathrm{ZAR})\end{array}$ & Source \\
\hline \multicolumn{3}{|l|}{ Diagnostic costs } \\
\hline Xpert MTB/RIF cartridge & R110.00 & Cepheid, South Africa 2012 \\
\hline Xpert MTB/RIF test (including cartridge) & R166.20 & NHLS charges 2012 \\
\hline AFB microscopy (2 sputa) & R44.54 & NHLS charges 2011 \\
\hline Liquid culture, no growth & R88.71 & NHLS charges 2011 \\
\hline Liquid culture, growth (including LPA if available) & R261.00 & NHLS charges 2011 \\
\hline RIF, INH drug sensitivity testing (if not done by LPA) & R304.09 & NHLS charges 2011 \\
\hline Chest X-ray & R110.00 & 2011 public sector prices \\
\hline Empirical antibiotics & R11.00 & 2011 public sector prices \\
\hline Nurse visit & R71.14 & Department of Public Service and Administration, 2011 \\
\hline Doctor visit & R129.63 & Department of Public Service and Administration, 2011 \\
\hline Treatment costs & & $\begin{array}{l}\text { Drug costs: } 2011 \text { public sector prices } \\
\text { Outpatient care: WHO CHOICE (South Africa), health } \\
\text { facility no beds; monthly outpatient secondary-level } \\
\text { hospital for DR-TB } \\
\text { Inpatient care: WHO CHOICE tertiary-level hospital }{ }^{16}\end{array}$ \\
\hline Drug-sensitive TB & R2 768.00 & \\
\hline RIF mono-resistant TB & R17 329.00 & \\
\hline INH mono-resistant TB & R4 931.00 & \\
\hline MDR-TB & R55 525.00 & \\
\hline XDR-TB & R205 910.00 & \\
\hline
\end{tabular}

Table 3. 2014 results of Xpert/culture v. Xpert/Xpert pulmonary TB diagnostic algorithm (2011 ZAR)

\begin{tabular}{|c|c|c|c|c|}
\hline Base case scenario & $\mathrm{X} / \mathrm{C}$ & $\mathbf{X} / \mathbf{X}$ & $\begin{array}{l}\text { Incremental change } \\
\text { of } \mathrm{X} / \mathrm{X} \text { over } \mathrm{X} / \mathrm{C}\end{array}$ & $\%$ \\
\hline Number of TB cases diagnosed, $N$ & 426558 & 418079 & -8479 & -2 \\
\hline Number of MDR-TB cases diagnosed, $N$ & 11033 & 10861 & -172 & -2 \\
\hline Number of TB cases initiated on treatment, $N$ & 359274 & 361136 & +1862 & +1 \\
\hline Number of MDR-TB cases initiated on treatment, $N$ & 9341 & 9397 & +56 & +1 \\
\hline Total annual cost of PTB diagnosis, ZAR & R1 095 million & R969 million & -R126 million & -11 \\
\hline Cost per patient evaluated for TB, ZAR & $\mathrm{R} 427$ & R376 & $-\mathrm{R} 51$ & -12 \\
\hline Cost per case diagnosed, ZAR & R2 566 & R2 317 & $-\mathrm{R} 249$ & -10 \\
\hline Cost per case initiated on treatment, ZAR & R3 046 & R2 682 & $-\mathrm{R} 364$ & -12 \\
\hline Patients with TB diagnosis within 1 week, $\%$ & $87 \%$ & $89 \%$ & $+2 \%$ & +2 \\
\hline Total annual cost PTB diagnosis and treatment, ZAR & R2 312 million & R2 194 million & -R118 million & -6 \\
\hline Cost per TB patient treated, ZAR & R6 435 & R6 076 & $-\mathrm{R} 359$ & -5 \\
\hline
\end{tabular}

annual cost saving of R126 million (US\$17.4 million), or $11 \%$ of total cost of diagnosis.

The cost per TB case initiated on treatment among HIV-positive, first Xpert-negative patients is R3 046 under X/C, compared with R2 682 under X/X (12\% less). Cost savings from an X/X algorithm could be realised immediately, although their total value would be proportional to the extent of the roll-out of Xpert in 2012 and 2013 (results not shown).
Under the X/X algorithm, 2\% fewer TB cases and 2\% fewer MDRTB cases are diagnosed because Xpert is less sensitive than culture. However, because loss to follow-up during the diagnostic process is expected to be substantially lower than in X/C, $1 \%$ more TB cases and $1 \%$ more MDR-TB cases are initiated on appropriate TB treatment under the $\mathrm{X} / \mathrm{X}$ algorithm. This in turn would raise overall treatment costs by $1 \%$. Therefore, the total (diagnosis and treatment) annual 


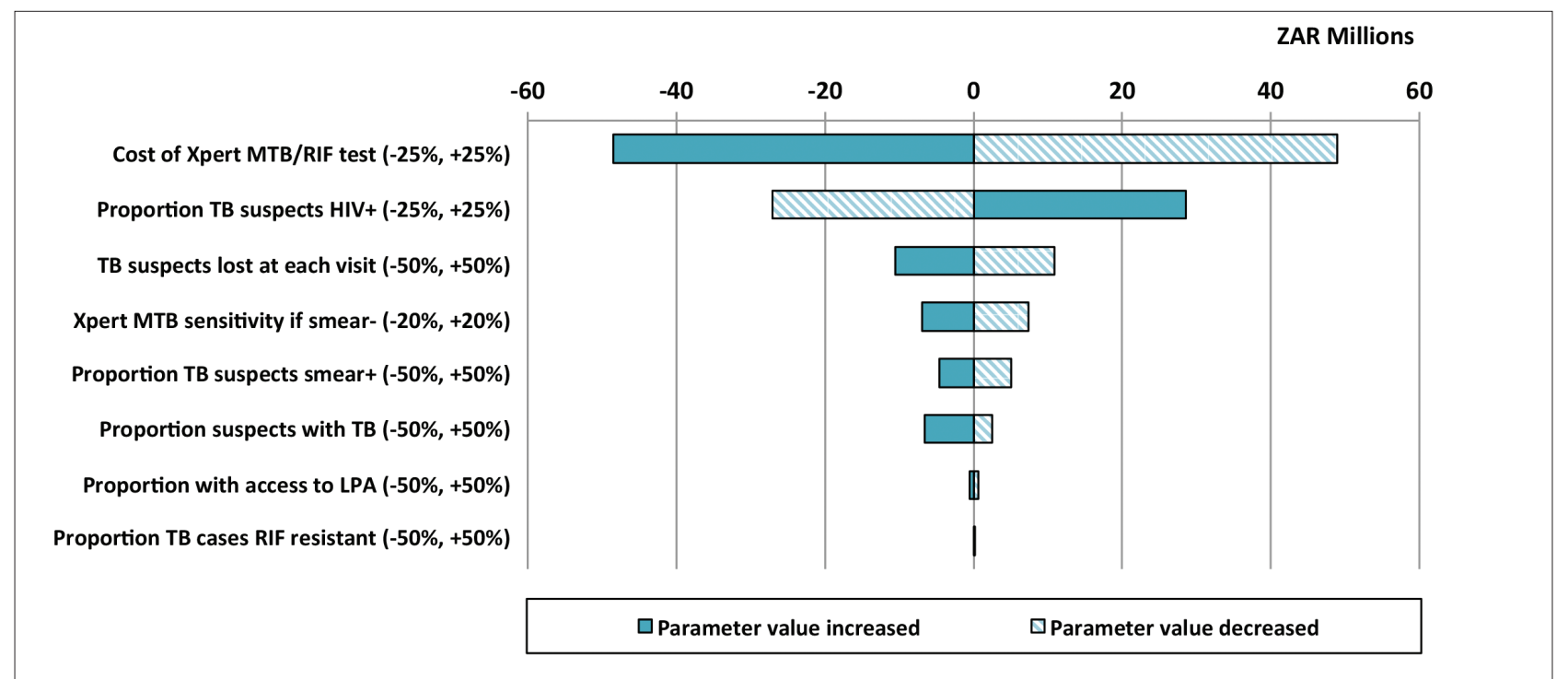

Fig. 2. Tornado diagram of difference of total annual diagnostic cost (millions ZAR, 2011) between Xpert/culture and Xpert/Xpert as a result of percentage change in assumed parameter values. R0 set at base case difference of -R118 million.

cost of SA's PTB programme would be R2 194 million under X/X, which is $6 \%$ (R118 million) less than the R2 312 million under X/C.

\section{Sensitivity analysis}

Of the parameters tested in sensitivity analysis, the incremental cost of the $\mathrm{X} / \mathrm{X}$ algorithm was sensitive only to variations in the cost of an Xpert test. However, in August 2012, a public-private partnership with major international donors announced a buy-down of Xpert MTB/RIF cartridges so that the price of US\$9.98 will not increase before $2020 .^{15}$

Systematic variation in this and all other parameters still led to annual cost savings from using an X/X diagnostic algorithm (Fig. 2).

The number of cases of $\mathrm{TB}$ diagnosed and treated under each algorithm was sensitive to variation in the sensitivity of Xpert in AFBnegative TB. The assumed Xpert sensitivity of AFB-negative TB is $79 \%$, lower than the sensitivity of culture. Therefore in most instances the total number of cases diagnosed in the $\mathrm{X} / \mathrm{X}$ algorithm is slightly lower (average $-2 \%$ ) than the $\mathrm{X} / \mathrm{C}$ algorithm. In these same scenarios, however, the number of TB patients initiated on treatment under $\mathrm{X} / \mathrm{X}$ remains slightly higher (average $+1 \%$ ) because of the shortened time to diagnosis and consequent reduction in loss of patients.

\section{Discussion}

Declining international funding for HIV and TB programmes ${ }^{19}$ makes it essential that available resources be used as efficiently as possible to achieve public health goals. Newly-available diagnostic technologies for TB promise vastly improved diagnosis of the disease, particularly among the large population of TB/HIV co-infected patients in many low- and middle-income countries. However, access to these technologies poses the challenge of identifying the most efficient ways to use them, within the budgetary constraints of the overall public health systems.

We used a model parameterised for SA to compare two strategies for diagnosing TB in HIV co-infected patients where Xpert MTB/ RIF technology is available. We found that for almost all parameter values considered, a diagnostic algorithm that follows an initial negative Xpert with a second Xpert, rather than with culture combined with examination, X-ray and antibiotics, reduces costs substantially, without meaningfully affecting the number of patients initiating TB treatment.

The estimated R118 million annual saving from the X/X algorithm is roughly equal to the cost of providing isoniazid as prophylactic therapy for all HIV-infected patients who are found not to have active TB disease. The $\mathrm{X} / \mathrm{X}$ algorithm is also likely to reduce patientlevel costs and treatment delays, directly benefiting those with TB. Furthermore, reducing patient loss to follow-up before treatment initiation may diminish the duration of exposure to active TB among patients' families, co-workers and other contacts, and hence reduce TB transmission. The combination of budget savings and benefits to patients and their households argues that SA policymakers should seriously consider the proposed $\mathrm{X} / \mathrm{X}$ strategy.

As large-scale rollout of Xpert MTB/RIF is just beginning in SA, it is uncertain how implementation will progress and what the results will be. We therefore had to make several assumptions that influence our results. For example, our analysis assumed that guidelines will be followed and tests performed correctly, but healthcare worker preferences and patient behaviour will certainly affect implementation of either algorithm. The pilot roll-out in SA indicates that laboratory technicians, clinicians and patients will prefer X/X's ease of use and rapid results over the multiple visits, reliance on clinical interpretation and delayed results when using culture and clinical diagnosis. ${ }^{20}$

While $\mathrm{X} / \mathrm{X}$ is one obvious alternative diagnostic algorithm for the present SA situation, other diagnostic sequences and combinations could be considered. For example, in some countries it may be desirable to use Xpert as a second test after a negative sputum smear. The value of the additional procedures that are combined with culture in the $\mathrm{X} / \mathrm{C}$ algorithm - examination, $\mathrm{X}$-ray, and antibiotics should also be explored, as they contribute substantially to the cost of the algorithm.

To reduce the overall cost of $\mathrm{TB}$ diagnosis, strategies should be explored to reduce the number of Xpert-negative HIV-infected patients still considered TB suspects, such as presumptive antibiotic treatment. Further operational research into the diagnosis of extra-pulmonary $\mathrm{TB}$, in particular the collection of specimens from extrapulmonary foci at primary healthcare level, could also reduce the number of Xpertnegative patients who are symptomatic but undiagnosed.

While these findings pertain to SA, they are applicable to other countries that are debating the appropriate placement of Xpert within their TB diagnostic algorithms, especially countries with high rates of TB/HIV co-infection. Once the initial investment in Xpert technology has been made, analysis suggests that performing a second Xpert test instead of a culture will conserve scarce clinical 
and laboratory skills, reduce costs, relieve patients of having to make multiple clinic visits, and accelerate availability of results.

Countries that do not replace smear microscopy with Xpert across all laboratories, but rather establish Xpert capacity in a few central ones, may still find that our proposed algorithm has cost advantages for diagnosing TB in patients who are initially AFB-negative, though this would require further analysis using different model parameters.

Acknowledgements. This study was funded by the South Africa Mission of the US Agency for International Development under the terms of Cooperative Agreement No. 674-A-00-09-00018-00 (GMR, KS, LL and SR) and under Agreement No. 674-A-00-08-0007-00 to Right to Care (IS). KS received additional training support from Fogarty International Center ICOHRTA AIDS/TB Grant No. U2RTW007373. The funders had no role in study design, analysis, decision to publish, or preparation of the manuscript.

KS designed the study, updated the model and wrote the first manuscript draft. GMR built and parameterised the model. LL and IS decided on scenarios and reviewed outputs. WS helped design the study and provided input data. SR helped design the study and edited the draft manuscript. All authors reviewed the paper.

The authors declare that they have no conflicts of interest. WS is the head of the NHLS National Priority Programs, and, as such, has the responsibility for purchasing Xpert MTB/RIF.

\section{References}

1. Boehme CC, Nicol MP, Nabeta P, et al. Feasibility, diagnostic accuracy, and effectiveness of decentralised use of the Xpert MTB/RIF test for diagnosis of tuberculosis and multidrug resistance : a multicentre implementation study. Lancet. 2011;6736(11):1-11. [http://dx.doi.org/10.1016/S01406736(11)60438-8]

2. Bruchfeld J, Aderaye G, Palme IB, Bjorvatn B, Kallenius G, Lindquist L. Sputum concentration prevalence of HIV improves diagnosis of tuberculosis in a setting with a high prevalence of HIV. Trans R Soc Trop Med Hyg 2000;94:677-680. [http://dx.doi.org/10.1016/S0035-9203(00)90230-X]

3. Eyangoh SI, Torrea G, Tejiokem MC, et al. HIV-related incremental yield of bleach sputum Microbiol Infect Dis 2008;27(9):849-855. [http://dx.doi.org/10.1007/s10096-008-0516-4]
4. Stop TB Department. Rapid Implementation of the Xpert MTB/RIF diagnostic test. Geneva: World Health Organization, 2011. http://whqlibdoc.who.int/publications/2011/9789241501569_eng.pdf (accessed 11 March 2011)

5. Scott LE, McCarthy K, Gous N, et al. Comparison of Xpert MTB/RIF with other nucleic acid technologies for diagnosing pulmonary tuberculosis in a high HIV prevalence setting: a prospective study. PLoS Medicine 2011:8(7):e1001061. [http://dx.doi.org/10.1371/journal.
par prospective stu

6. Boehme CC, Nabeta P, Hillemann D, et al. Rapid molecular detection of tuberculosis and rifampin resistance. N Engl J Med 2010;363(11):1005-1015. [http://dx.doi.org/10.1056/ rifampin resistance.

7. Getahun H, Harrington M, O'Brien R, Nunn P. Diagnosis of smear-negative pulmonary tuberculosis in people with HIV infection or AIDS in resource-constrained settings : informing
ting tuberculosis in people with HIV infection or AIDS in resource-constrained settings : informing
urgent policy changes. Lancet 2007;369(9578):2042-2049. [http://dx.doi.org/10.1016/S0140-

8. World Health Organization. Global Tuberculosis Control: WHO Report 2011. Geneva: World Health Organization, 2011. http://www.who.int/tb/publications/global_report/2011/en/index.html (accessed 1 September 2012).

9. Directorate Drug-Resistant TB TB \& HIV. Management of Drug-Resistant Tuberculosis: Policy Guidelines. Pretoria: Government Press, 2011. http://www.doh.gov.za/docs/policy/2012/TBpolicy.pdf (accessed 11 March 2011)

10. Meyer-Rath G, Schnippel K, Long L, et al. The impact and cost of scaling up GeneXpert MTB/RIF in South Africa. PLoS ONE 2012;7(5):e36966. [http://dx.doi.org/10.1371/journal.pone.0036966]

11. Lawn SD, Brooks SV, Kranzer K, et al. Screening for HIV-associated tuberculosis and rifampicin resistance before antiretroviral therapy using the Xpert MTB/RIF assay: a prospective study. PLoS Medicine 26;8(7):e1001067. [http://dx.doi.org/10.1371/journal.pmed.1001067]

12. Andrews JR, Lawn SD, Rusu C, et al. The cost-effectiveness of routine tuberculosis screening with Xpert MTB/RIF prior to initiation of antiretroviral therapy : a model-based analysis. Aids 2012;26(8):987995. [http://dx.doi.org/10.1097/QAD.0b013e3283522d47]

13. Actuarial Society of South Africa. AIDS Demographic model. ASSA2003 lite, 2003. http://aids. actuarialsociety.org.za/ (accessed 11 March 2011).

14. TB Control Programme. TB Provincial Quarterly Progress Reports 2011. http://www.doh.gov.za/docs/ policy/2007/part4.pdf (accessed 1 September 2012)

15. Gates Foundation, PEPFAR, USAID, UNITAID Finalize Partnership to Cut Price of TB Test. Philanthropy News Digest. 8 August 2012. http://foundationcenter.org/pnd/news/story jhtml?id=388200003 (accessed 1 September 2012).

16. Choosing Interventions that are Cost-Effective. WHO-CHOICE unit cost estimates for service delivery - Estimation file. 2011. http://www.who.int/choice/costs/en/ (accessed 1 September 2012).

17. Dheda K, Shean K, Zumla A, et al. Early treatment outcomes and HIV status of patients with extensively drug-resistant tuberculosis in South Africa: A retrospective cohort study. Lancet 2010;375(9728):1798-1807. [http://dx.doi.org/10.1016/S0140-6736(10)60492-8]

18. Oanda. US\$ZAR Average exchange rate 1 Jan 2011-31 Dec 2011 [Internet]. Historical Exchange Rates. 2012;1-2. http://www.oanda.com/currency/historical-rates/ (accessed 1 September 2012).

19. Raviglione M, Zumla A, Marais B, Horton R, Motsoaledi A. A sustainable agenda for tuberculosis contro and research. The Lancet 2012;379(9821):1077-1078. [http://dx.doi.org/10.1016/S0140-6736(12)60373-0]

20. Clouse K, Page-Shipp L, Dansey H, et al. Implementation of Xpert MTB/RIF for routine point-of-care diagnosis of tuberculosis at the primary care level. S Afr Med J 2012;102(10):805-807. [http://dx.doi. org/10.7196/samj.5851]

21. South African National AIDS Council. National Strategic Plan on HIV, STIs, and TB 2012-2016. 2012 http://www.doh.gov.za/docs/stratdocs/2012/NSPfull.pdf (accessed 1 September 2012).

22. Weyer K, Brand J, Lancaster J, Levin J, Van der Walt M. Determinants of multidrug-resistan tuberculosis in South Africa: Results from a national survey. S Afr Med J 2007;97(11):1120-1128.

Accepted 28 September 2012 